\title{
Cellular in vitro Assays in the Diagnosis of Hymenoptera Venom Allergy
}

\author{
K. Scherer ${ }^{a} \quad$ J.M. Weber ${ }^{\text {b }} \quad$ T.M. Jermann ${ }^{b} \quad$ A. Krautheim ${ }^{a} \quad$ E. Tas ${ }^{a}$ \\ E.V. Ueberschlag ${ }^{b}$ M. Cammaratab A.J. Bircher ${ }^{a}$

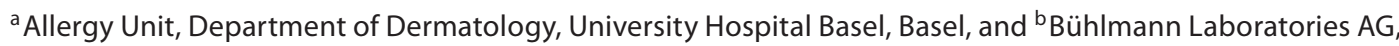 \\ Schoenenbuch, Switzerland
}

\section{Key Words}

Anaphylaxis $\cdot$ Basophils $\cdot$ CD63 $\cdot$ Hymenoptera venom $\cdot$

Hymenoptera venom allergy $\cdot \lg \mathrm{E} \cdot$ Skin tests

Sulfidoleukotriene production · CAST $\cdot$ Flow-CAST

\begin{abstract}
Background: The current diagnostic procedures of anaphylactic reactions to hymenoptera stings include intradermal tests, venom-specific $\lg \mathrm{E}$ (slgE) and possibly sting challenge tests. Sometimes, the culprit insect remains unidentified. The usefulness of the cellular assays CAST ${ }^{\circledR}$-ELISA and Flow$\mathrm{CAST}^{\circledR}$ in the management of hymenoptera venom allergy was investigated. Methods: 134 patients with systemic reactions after a yellow jacket wasp and/or honey bee sting and 44 healthy controls underwent skin tests, as well as determination of slgE (CAP-FEIA), leukocyte sulfidoleukotriene release (CAST-ELISA) and basophil CD63 expression (FlowCAST) upon insect venom stimulation. The clinical diagnosis based on the history alone served as reference. Sensitivity, specificity, and positive and negative predictive value of all methods were compared. Concordance and correlations among methods were calculated. Results: Sensitivity and specificity of all in vitro tests were consistently high. The combination of all tests (skin tests, slgE, combined cellular assays) yielded a positive predictive value of $100 \%$ for both venoms, if all 3 were positive, and a negative predictive value of $100 \%$, if at least 1 test was positive. Relative specificities were considerably higher for the cellular assays (honey bee: CAST 91.1\%, Flow-CAST 85.7\%; yellow jacket wasp: CAST
\end{abstract}

\section{KARGER \\ Fax +41613061234 \\ E-Mail karger@karger.ch}

(c) 2008 S. Karger AG, Basel

www.karger.com
2008 S. Karger AG, Basel

Accessible online at:

www.karger.com/iaa
98.4\%, Flow-CAST 92.1\%) and allow the detection of the culprit insect in patients with reactivity to both insects. The concordance between methods was good. There is no correlation between severity of clinical reaction and cellular assays. Conclusion: CAST-ELISA and Flow-CAST are valuable additional diagnostic tools for establishing the true culprit insect in patients with unclear clinical history or sensitization to both insects.

Copyright $\odot 2008$ S. Karger AG, Basel

\section{Introduction}

Systemic hypersensitivity reactions to hymenoptera stings have been reported to occur in $0.8-5 \%$ of the general population [1-3], the vast majority of these being immediate-type, IgE-mediated reactions. They may be very severe and even life-threatening with $0.09-0.45$ deaths per million within the general population $[4,5]$. The insects most frequently involved are honey bee $(\mathrm{HB})$ and yellow jacket (YJ) wasp.

Standard diagnostic procedures include skin tests (ST, skin prick tests or preferably intradermal tests with progressive dilutions up to $1 \mu \mathrm{g} / \mathrm{ml}$ of insect venom extracts) and determination of specific $\operatorname{IgE}(\mathrm{sIgE})$ in the serum against $\mathrm{HB}$ or $\mathrm{YJ}$ venom. Occasionally, venom-specific IgG response is added to the diagnostic armament. Neither the absolute amount of venom-specific IgE nor of IgG allows the prediction of the severity of a possible future reaction to a sting [6]. Sting challenge tests are con-

Correspondence to: Prof. Andreas J. Bircher

Allergy Unit, Department of Dermatology, University Hospital Basel Petersgraben 4

$\mathrm{CH}-4031$ Basel (Switzerland)

Tel. +41 61265 4359, Fax +41 61265 4885, E-Mail abircher@uhbs.ch 
sidered the gold standard, although the negative predictive value is low. Also, they pose the risk of life-threatening anaphylaxis and are therefore only performed in few specialized allergy units [3].

Although these combined techniques allow an accurate diagnosis in the majority of cases, a sizeable number of patients exists in whom, despite a convincing clinical history, ST and/or venom-specific IgE remain negative or ambiguous, not taking into account the cases with unclear clinical history.

Golden et al. [7] investigated 307 patients with a clear history of systemic immediate-type reaction after a hymenoptera sting. Ninety-nine patients (32\%) had negative ST, of which 57\% (56 patients) had negative sIgE and only 7 patients high levels of sIgE. Anliker et al. [8] found negative ST and negative or low-level SIgE in $24 \%$ of patients with convincing clinical history. Golden et al. [7] showed that these patients are at risk of another systemic reaction if stung again, and also that ST and venom-specific $\operatorname{IgE}$ are frequently (up to 20\%) discordant.

In addition, the timing of diagnostic procedures in relation to the anaphylactic event seems to be crucial. Based on 41 patients, Goldberg and Confino-Cohen [9] showed that up to one quarter of the patients exhibited negative ST and sIgE within 1 week of the original systemic reaction.

Up to $50 \%$ of insect venom-allergic patients show dual sensitivity to $\mathrm{HB}$ and $\mathrm{YJ}$ venoms when analyzed by ST or $\operatorname{sIgE}[10,11]$; however, many of these double positivities do not seem to be clinically relevant [10].

These difficulties, together with the risk and insecurity of diagnostic sting challenges, require the development and evaluation of additional diagnostic techniques.

In recent years, 2 new and promising in vitro test methods have been introduced: the sulfidoleukotriene (sLT) release by basophils, assessed by ELISA $\left(\mathrm{CAST}^{{ }^{\circledR}}\right.$ ELISA) and the activation of the basophilic CD63 marker as measured by flow cytometry (Flow-CAST ${ }^{\circledR}$ ). The latter test is also known as basophil activation test (BAT) or flow-cytometric allergen stimulation test (FAST).

CAST-ELISA assesses the in vitro release of sLT from blood leukocytes of presumably allergic patients upon stimulation with various doses of the allergen. This technique has been shown to be a valuable diagnostic tool in certain inhalant, food, occupational and drug allergies [12-14].

Flow-CAST investigates the allergen-induced in vitro activation of basophils as determined by the demonstration of the CD63 molecule on the basophil membrane.
CD63 is normally expressed on the inside of vesicle membranes. Under membrane-bound IgE cross-linking, the fusion of the vesicle to the plasma membrane allows the expression of CD63 on the external membrane and can then be detected by flow cytometry $[15,16]$. Several reports proved its potential role in inhalant, food, latex and drug allergy [17-19].

The main aim of this study was to compare the results of different in vivo and in vitro methods with the clinical diagnosis obtained by comprehensive evaluation of the clinical history which served as the gold standard. Our study investigates the usefulness of CAST-ELISA and Flow-CAST in the diagnosis and management of hymenoptera venom allergy. Sensitivity, specificity, negative (NPV) and positive predictive value (PPV) of ST, sIgE, Flow-CAST and CAST-ELISA in comparison to the clinical history were investigated in 134 patients with systemic reactions after hymenoptera stings, not yet under specific immunotherapy (SIT). The relative specificities to the culprit insect as well as concordances and correlations among methods are also shown.

\section{Material and Methods}

Data from 200 consecutive patients with a suspected systemic reaction to hymenoptera stings who reported to the Allergy Unit of the University Hospital in Basel between December 1999 and May 2004 were collected. No restrictions were made as to age, sex, medications, other diseases or any other condition. Thirty-seven patients were excluded for reasons such as insufficient medical history $(n=22)$, unclear reaction $(n=11)$ or technical reasons $(\mathrm{n}=4)$ and a further 29 patients because they were currently under SIT. The remaining 134 patients (age range 7-74 years, mean 38.9 \pm 17.4 years; 82 males, 52 females) had reacted to stings of either HB $(n=55)$ or YJ $(n=67)$ or both $(n=12)$.

According to the classification by Mueller [20], 11 had experienced a grade I allergic reaction, 33 a grade II, 51 a grade III and 39 a grade IV anaphylactic reaction.

Forty-four nonsensitized subjects served as volunteer controls (age range 18 and 60 years, mean $39.2 \pm 11.7$ years; 12 males, 32 females). Approval of the Ethics Committee of the University Hospital of Basel was obtained, as well as informed consent.

The patients underwent a routine allergologic evaluation consisting of a detailed history of the event, intradermal ST, determination of sIgE against $\mathrm{HB}$ and $\mathrm{YJ}$ venom in the serum by CAPFEIA (UniCAP 100; Pharmacia, Uppsala, Sweden) and 2 insect venom-induced cellular activation assays (CAST-ELISA and Flow-CAST; Bühlmann Laboratories AG, Schoenenbuch, Switzerland).

Intradermal ST were performed on the volar side of the forearm in a titrating fashion starting with the injection of $0.05 \mathrm{ml}$ of $\mathrm{HB}$ and $\mathrm{YJ}$ venom solutions, each containing $0.0001 \mu \mathrm{g} / \mathrm{ml}$ of venom protein extract (ALK-Abelló, Horsholm, Denmark). Histamine $(0.1 \mathrm{mg} / \mathrm{ml}$; Allergopharma, Reinbek, Germany) and albu- 
min diluents served as controls. In case of negativity of the first test, the test dose was increased 10 -fold every 15 min until either a positive reaction occurred or the highest dose of $1 \mu \mathrm{g} / \mathrm{ml}$ of both venoms was reached. A positive reaction was defined as a wheal larger than the negative control after $15 \mathrm{~min}$ [21].

Control subjects underwent a detailed interrogation regarding prior hymenoptera stings, medications and any other health condition. Healthy volunteers without any prior anaphylactic reaction to hymenoptera venom were enrolled. Skin prick tests were performed on the volar forearm with 3 concentrations of $\mathrm{HB}$ and YJ venom each (10, 100 and $300 \mu \mathrm{g} / \mathrm{ml}$; ALK-Abelló). Histamine (10 mg/ml; ALK-Abelló) and $0.9 \% \mathrm{NaCl}$ served as controls. A test reaction was evaluated as positive if the wheal size was $>3 \mathrm{~mm}$ after $15 \mathrm{~min}$ and a flare was present [21]. CAST-ELISA, FlowCAST and sIgE were also determined.

\section{CAST-ELISA and Flow-CAST}

CAST-ELISA and Flow-CAST were performed by the manufacturer (Bühlmann Laboratories AG) according to the standard protocols included in the commercially available test kits. Cells were stimulated with IL-3 and incubated for $40 \mathrm{~min}$ with several final concentrations of insect venom $(2,5,10$ and $20 \mathrm{ng} / \mathrm{ml}$ for CAST-ELISA; 5, 12.5 and $25 \mathrm{ng} / \mathrm{ml}$ for Flow-CAST; venom: ALKAbelló).

\section{Statistical Methods}

Data of patients' and control subjects' age distribution, of CAST-ELISA (pg/ml sLT net release) and Flow-CAST (percentage of CD63+ basophils) are expressed as means $\pm 1 \mathrm{SD}$. Baseline characteristics of the cellular assays were all nonnormally distributed and were compared within and between control subjects and patients using the Mann-Whitney $\mathrm{U}$ test for independent and the Wilcoxon signed-rank test for related samples. The differences of the cellular reactions to the stimulus (positive control, HB, YJ) within and between patient and control subgroups were analyzed using the independent $\mathrm{t}$ test for FLOW-CAST (normally distributed samples) and the median test for CAST-ELISA (nonnormally distributed samples). The concordance of all in vivo and in vitro tests was calculated using the $\kappa$ test for agreement. The correlations between the different methods were analyzed using the Spearman rank correlation coefficient (rs). Possible correlations between the magnitude of the test responses to the allergens and the severity of clinical symptoms were determined using ANOVA on anaphylaxis grades (Kruskal-Wallis H test). The McNemar test was used to test the changes in reacting to the nonculprit insect venoms between the different test methods (table $4 \mathrm{a}$ and $\mathrm{b}$ ). $\mathrm{p} \leq$ 0.05 were considered significant.

\section{Results}

\section{sLT Production}

The basal (spontaneous) mediator release (CAST-ELISA) was compared with the sLT release upon stimulation with the stimulation control (anti-FceRI antibody, clone 22E7 [22]) as well as HB and YJ venom at the optimum allergen concentration for both patients and control sub- jects (fig. 1a). The stimulation capacity of leukocytes varied considerably among individuals. Between 15 and 30\% (stimulated by allergens) and up to $70 \%$ (stimulated by stimulation control) of so-called high-sLT releasers exhibited sLT levels above the upper detection limit of 3,200 $\mathrm{pg} / \mathrm{ml}$. These sLT values were uniformly set at $3,200 \mathrm{pg} /$ $\mathrm{ml}$ and might therefore bias high sLT results (see correlation data below).

\section{CD63 Upregulation}

Basal (spontaneous) CD63 upregulation (Flow-CAST) was compared with CD63 expression upon stimulation with the stimulation control and $\mathrm{HB}$ and YJ venom at the optimum allergen concentration, for both patients and control subjects (fig. 1b). Two control subjects with large local but no systemic reactions showed elevated CD63 expression of 29 and $62 \%$, when tested with $\mathrm{HB}$ venom. After exclusion of these 2 controls, the mean CD63 expression $(4.3 \pm 2.3)$ did not differ from those of basal CD63 expression levels.

CD63 expression induced by $25 \mathrm{ng} / \mathrm{ml}$ of $\mathrm{HB}$ venom was significantly lower than with either stimulation control $(\mathrm{p}=0.0061)$ or YJ venom ( $\mathrm{p}=0.0255)$. The CD63 expression of control subjects upon venom stimulation was in the same range as the spontaneous CD63 levels of controls and patients.

\section{Diagnostic Potential of the Cellular Tests}

For the determination of the diagnostic potential of the cellular assays, the definition of the cutoff chosen for positivity is important, since both venom extracts may contain obligate nonspecific basophil stimulators that might cause false-positive reactions [23]. Therefore, HB and YJ allergen concentrations for stimulation must not be too high and the cutoff should be based on the evaluation of normal, nonsymptomatic controls. For CASTELISA, $67 \mathrm{HB}$-allergic, $78 \mathrm{YJ}$-allergic patients and 44 healthy volunteers were enrolled. The optimal threshold (cutoff point) to differentiate between negative and positive $\mathrm{HB}$ and $\mathrm{YJ}$ results was determined at 4 different allergen concentrations by plotting the true-positive results (in reference to the clinical history) against the false-positive results by ROC curves (data not shown). For both venoms, the curves followed the left-hand and then the top border, indicating high accuracy. The high sensitivity and specificity for $\mathrm{HB}$ and $\mathrm{YJ}$ are listed in table 1 . For CAST-ELISA the values selected fitted a net sLT release of $261 \mathrm{pg} / \mathrm{ml}$ for YJ and $266 \mathrm{pg} / \mathrm{ml}$ for HB at the bestmatching allergen concentration of $10 \mathrm{ng} / \mathrm{ml}$ each. The same procedure was applied for Flow-CAST by compar- 
Fig. 1. Basal and induced (stimulation control, HB and YJ venom) sLT releases (a) and CD63 expression (b) for control subjects and patients (means $\pm 1 \mathrm{SD}$ ). Medians (horizontal lines) are shown only for stimulated samples.
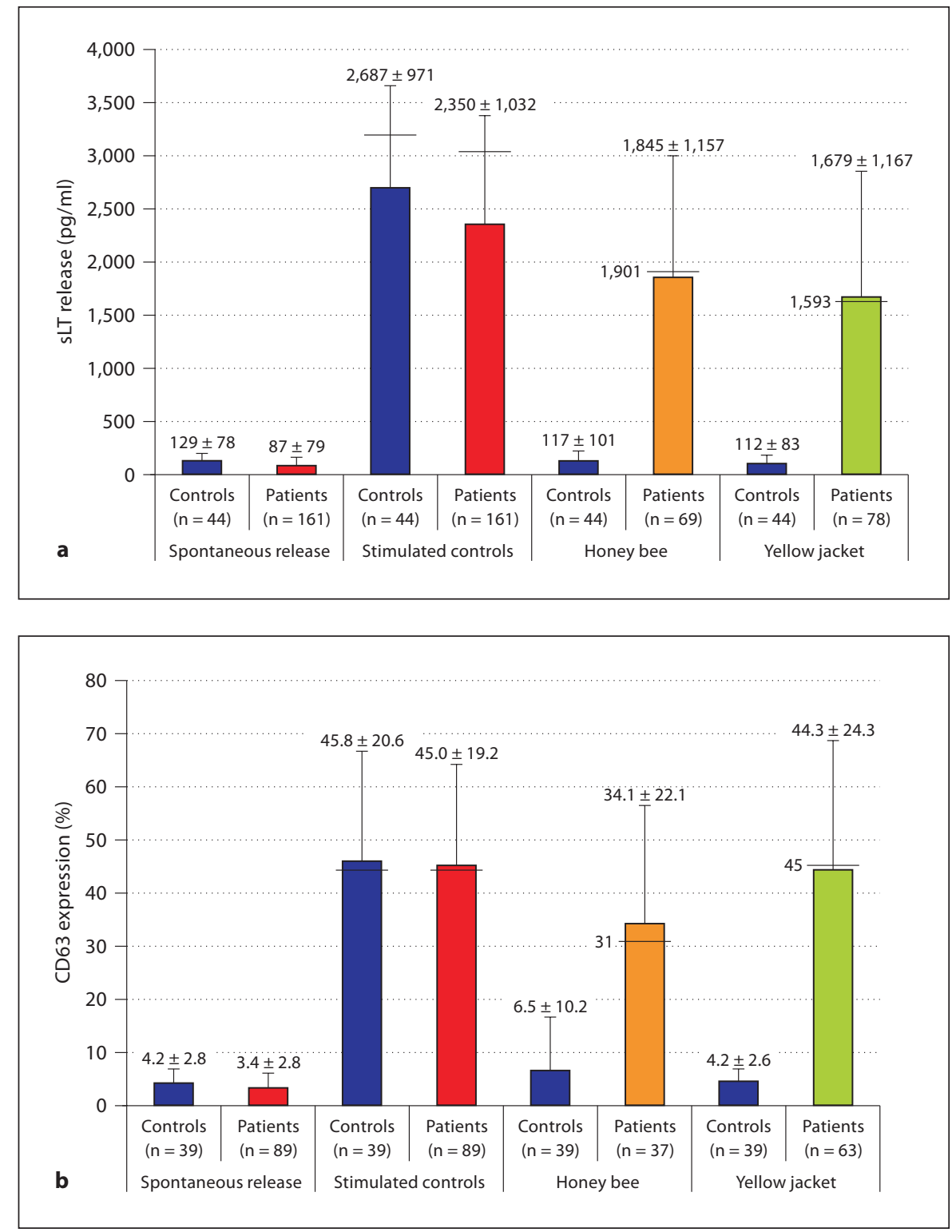

ing $19 \mathrm{HB}$ and $45 \mathrm{YJ}$ patients with the same controls $(\mathrm{n}=$ 39) using 3 different allergen concentrations. The selected values for sensitivity and specificity correspond to a CD63 expression on $\geq 10 \%$ of basophils for both insect venoms at the best-matching allergen concentration of 25 $\mathrm{ng} / \mathrm{ml}$ each.

The results of the ST, sIgE and cellular allergy assays were then correlated with the definitive clinical diagnosis. The number of individuals analyzed differed among the various test methods. One sIgE result of a control subject, some ST of the patients and 2 of the controls were not available. As the Flow-CAST method was in- troduced only in February 2002, the number of patients evaluated with this method was substantially lower. Separate results are shown for HB (table 1a) and YJ (table $1 b$ ). Twenty patients exhibiting an anaphylactic reaction to both insects were enrolled in both the $\mathrm{HB}$ and $\mathrm{YJ}$ evaluation.

\section{Predictive Values}

The combination of the cellular assays (at least 1 positive result in a patient) yielded sensitivities (HB: 94.7\%; YJ: 95.6\%) which were as high as the ones for ST. The combination of both cellular assays (both results positive 
Table 1. Sensitivity, specificity, PPV and NPV in relation to the clinical diagnosis for HB- and YJ-allergic patients and for the combination of all testing modalities (ST, sIgE, combined cellular assays)

a HB-allergic patients

\begin{tabular}{|c|c|c|c|c|c|c|c|}
\hline & CAST & Flow-CAST & $\begin{array}{l}\text { CAST and Flow- } \\
\text { CAST combined }\end{array}$ & CAP-FEIA & ST & $\begin{array}{l}1 \text { (of } 3 \text { ) methods } \\
\text { positive }\end{array}$ & $\begin{array}{l}\text { All } 3 \text { methods } \\
\text { positive }\end{array}$ \\
\hline Patients/controls, $\mathrm{n}$ & $67 / 44$ & $19 / 39$ & $19 / 39$ & $67 / 43$ & $63 / 42$ & $67 / 41$ & $65 / 44$ \\
\hline Sensitivity, $\%$ & 94.0 & 89.5 & 94.7 & 92.5 & 93.7 & 100 & 86.2 \\
\hline $95 \%$ CI, \% & $85.4-98.3$ & $66.9-98.7$ & $74.0-99.9$ & & & & \\
\hline Specificity, \% & 93.2 & 94.9 & 97.4 & 83.7 & 97.6 & 75.6 & 100 \\
\hline $95 \%$, CI \% & $81.3-98.6$ & $82.7-99.4$ & $86.5-99.9$ & & & & \\
\hline NPV & 0.911 & 0.895 & 0.972 & 0.878 & 0.911 & 1 & 0.830 \\
\hline PPV & 0.955 & 0.949 & 0.941 & 0.899 & 0.983 & 0.870 & 1 \\
\hline
\end{tabular}

b YJ-allergic patients

\begin{tabular}{llllllll}
\hline & CAST & Flow-CAST & $\begin{array}{l}\text { CAST and Flow- } \\
\text { CAST combined }\end{array}$ & CAP-FEIA & ST & $\begin{array}{l}\text { 1 (of 3) methods } \\
\text { positive }\end{array}$ & $\begin{array}{l}\text { All 3 methods } \\
\text { positive }\end{array}$ \\
\hline Patients/controls, n & $78 / 44$ & $45 / 39$ & $45 / 39$ & $79 / 43$ & $77 / 42$ & $79 / 44$ & $77 / 44$ \\
$\begin{array}{l}\text { Sensitivity, \% } \\
\text { 95\% CI, \% }\end{array}$ & 88.5 & 86.7 & 95.6 & 92.4 & 97.4 & 100 & 88.3 \\
Specificity, \% & $79.2-94.6$ & $73.2-94.9$ & $84.9-99.5$ & & & \\
$\quad 95 \%$ CI, \% & 84.5 & 97.4 & 100 & 93.0 & 92.9 & 86.4 & 100 \\
NPV & 0.824 & 0.864 & 0.947 & 0.870 & 0.951 & 1 & 0.830 \\
PPV & 0.972 & 0.975 & 1 & 0.961 & 0.962 & 0.929 & 1 \\
\hline
\end{tabular}

Positivity was declared if (1) 1 of the tests was positive and (2) if all tests were positive.

in a control subject) yielded specificities (HB: 97.4\%; YJ: $100 \%)$ which were higher than for ST.

Of special importance for clinical situations is the fact that the combination of all 3 methodologies, ST, CAPFEIA and combined cellular assays, achieved a sensitivity of $100 \%(\mathrm{NPV}=1)$ for both HB and YJ. None of the controls had positive results in all 3 methodologies (specificity $100 \%$, PPV = 1; table 1).

\section{Concordance}

All 4 methods showed K ( $\kappa$ test) values between 0.66 and 0.84 to each other, with a tendency of somewhat higher values for $\mathrm{HB}$ (table 2). In $\mathrm{HB}$, the cellular assays are advantageous to $\operatorname{sgE}(\mathrm{K}=0.77)$. Overall, the agreement to the clinical diagnosis was very stable with $\mathrm{K}$ values above 0.81 (except 0.77 in HB CAP-FEIA) for all in vitro tests, indicating an acceptable performance of all methods in the diagnosis of hymenoptera venom allergy.

\section{Correlations}

The absolute correlations as calculated by the Spearman rank correlation coefficient (rs) between the different test methods were only weak or not existent (table 3). This phenomenon might be due to the fact that approximately $30 \%$ of the CAST-ELISA results were above the upper detection limit of $3,200 \mathrm{pg} / \mathrm{ml}$ sLT release. All data above this upper limit were considered as $3,200 \mathrm{pg} / \mathrm{ml}$ net release and did, therefore, not reflect the effective magnitude of stimulation by the venom allergens, possibly leading to negatively biased CAST-ELISA correlations.

\section{Relative Specificities}

To elucidate the relative specificity for identifying the true culprit insect as defined by the clinical history, the number of false-positive results for YJ in clinically $\mathrm{HB}$ allergic patients and vice versa (table $4 \mathrm{a}$ and $\mathrm{b}$ ) was determined. This showed a much higher relative specificity of the cellular in vitro allergy assays (HB: CAST-ELISA 91.1\%, Flow-CAST: 85.7\%; YJ: CAST-ELISA 98.4\%, Flow- 
Table 2. Concordance (K values) between the different test methods and their agreement with the clinical diagnosis calculated using the $\kappa$ test for agreement

\begin{tabular}{llllll}
\hline HB/YJ & CAST & Flow-CAST & CAP-FEIA & ST & Clinical diagnosis \\
\hline CAST & & 0.81 & 0.71 & 0.82 & 0.87 \\
Flow-CAST & 0.71 & & 0.73 & 0.70 & 0.84 \\
CAP-FEIA & 0.69 & 0.66 & & 0.72 & 0.77 \\
ST & 0.71 & 0.76 & 0.82 & & 0.90 \\
Clinical diagnosis & 0.81 & 0.83 & 0.84 & 0.91 & \\
\hline
\end{tabular}

K values: $>0.6$ good agreement; $>0.8=$ very good agreement; $1=$ absolute agreement.
Table 3. Correlations between the different test methods determined by the Spearman rank correlation coefficient (rs)

\begin{tabular}{lrlll}
\hline HB/YJ & \multicolumn{1}{l}{ CAST } & Flow-CAST & CAP-FEIA & ST \\
\hline CAST & & $0.08(0.7345)$ & $0.03(0.7964)$ & $0.13(0.3173)$ \\
Flow-CAST & $0.47(0.0011)$ & & $0.25(0.1328)$ & $0.25(0.1259)$ \\
CAP-FEIA & $-0.01(0.9256)$ & $0.03(0.8120)$ & & $0.41(0.0002)$ \\
ST & $0.07(0.5605)$ & $0.28(0.0268)$ & $0.42(<0.0001)$ & \\
\hline
\end{tabular}

Figures in parentheses are $\mathrm{p}$ values.
CAST 92.1\%) than of any of the other tests which reached statistical significance. The reciprocal value of the relative specificity corresponds to the value of nonrelevant sensitization which is much lower in the cellular assays than in the CAP-FEIA and ST. The high specificity of the cellular assays is only partly offset by a small loss of sensitivity. In case of HB-positive patients, the sensitivity of CAST-ELISA remains well at the same level as that of CAP-FEIA and ST. In YJ, sensitivity of the cellular assays remains still high, although lower than for CAP-FEIA and ST. The small loss of sensitivity is, however, discrete if compared to the considerable gain in relative specificity for the culprit insect. Due to the fact that Flow-CAST has only been introduced in 2002, not all patients were tested with all methods. The high relative specificity for identifying the culprit insect is, however, not affected by this. The relative specificities and sensitivities were also calculated for the smaller collective of patients in whom all 4 tests were available (numbers in parentheses in table 4 a). They do not differ greatly from the numbers of the whole study group.

To demonstrate that the cellular assays show negative results for the nonculprit insect in those patients that exhibit strongly positive values for CAP-FEIA and ST, the individual data of the patients with at least 1 positive test for the nonculprit insect are given in table $4 \mathrm{~b}$.

Cellular in vitro Assays in the Diagnosis of Hymenoptera Venom Allergy

\section{Severity of Anaphylaxis}

Finally, we tested the hypothesis that the cellular allergy tests may be suitable to predict the severity of an anaphylactic reaction due to an insect sting. A possible correlation between the anaphylaxis grade according to Mueller [20] and the magnitude of sLT release, CD63 upregulation and SIgE levels in response to the hymenoptera venoms was calculated using ANOVA on ranks (table 5). We found no significant differences, neither in the degree of sLT release and basophil activation nor in the sIgE levels between the groups of patients with clinical grades I-IV. In general, in vitro assays and ST seemed to better reflect the clinical diagnosis in $\mathrm{HB}$ than in YJ.

\section{Discussion}

This study represents a large collective of hymenoptera-allergic patients investigated with cellular activation tests. It analyzes in detail the usefulness of the 2 cellular allergy tests, CAST-ELISA and Flow-CAST, for the diagnosis of hymenoptera venom allergy in comparison to established testing procedures.

The recent literature concerning CAST-ELISA and particularly Flow-CAST suffers from minor or major differences in performing the tests (table 6) and from the

Int Arch Allergy Immunol 2008;146:122-132 
Table 4. Relative specificities of the various test methods for detecting the culprit insect and patients exhibiting positivity to the nonculprit insect

a Relative specificities

\begin{tabular}{|c|c|c|c|c|}
\hline & CAST & Flow-CAST & CAP-FEIA & ST \\
\hline \multicolumn{5}{|l|}{ HB positive, but YJ negative } \\
\hline YJ negative/YJ positive, $n$ & $41 / 4(12 / 0)$ & $12 / 2(10 / 2)$ & $26 / 18(8 / 4)$ & $22 / 14(7 / 5)$ \\
\hline Relative specificity for $\mathrm{HB}, \%$ & $91.1(100)$ & $85.7(83.3)$ & $59.1^{\mathrm{a}}(66.6)$ & $61.1^{\mathrm{a}}(58.3)$ \\
\hline Sensitivity for $\mathrm{HB}, \%$ & $91.1(83.3)$ & $85.7(83.3)$ & $93.2(91.7)$ & $91.7(83.3)$ \\
\hline \multicolumn{5}{|l|}{ YJ positive, but $H B$ negative } \\
\hline HB negative/HB positive, $\mathrm{n}$ & $60 / 1(35 / 1)$ & $35 / 3(33 / 3)$ & $30 / 30(15 / 21)$ & $36 / 21(28 / 8)$ \\
\hline Relative specificity for YJ, \% & $98.4(97.2)$ & $92.1(91.7)$ & $50.0^{\mathrm{b}, \mathrm{d}}(41.6)^{\mathrm{b}, \mathrm{e}}$ & $63.2^{\mathrm{b}}(77.8)$ \\
\hline Sensitivity for YJ, $\%$ & $88.5(88.9)$ & $86.8(88.9)$ & $95.0(91.6)$ & $98.2^{c}(100)$ \\
\hline
\end{tabular}

b Patients exhibiting positivity to the nonculprit insect with at least 1 method

\begin{tabular}{|c|c|c|c|c|c|c|c|c|}
\hline \multirow[t]{2}{*}{ Patient } & \multicolumn{4}{|c|}{ Test result for $\mathrm{HB}$} & \multicolumn{4}{|c|}{ Test result for YJ } \\
\hline & $\begin{array}{l}\text { ST positive } \\
\mu \mathrm{g} / \mathrm{ml}\end{array}$ & CAST & $\begin{array}{l}\text { Flow- } \\
\text { CAST }\end{array}$ & $\begin{array}{l}\text { CAP-FEIA } \\
\mathrm{kU} / \mathrm{l}\end{array}$ & $\begin{array}{l}\text { ST positive } \\
\mu \mathrm{g} / \mathrm{ml}\end{array}$ & CAST & $\begin{array}{l}\text { Flow- } \\
\text { CAST }\end{array}$ & $\begin{array}{l}\text { CAP-FEIA } \\
\mathrm{kU} / \mathrm{l}\end{array}$ \\
\hline HB 9 & neg. & 953 & 71 & 0.52 & neg. & 49 & 62 & 0.34 \\
\hline HB 80 & 0.1 & 611 & 20 & 3.22 & 0.1 & 7 & 2 & 0.34 \\
\hline HB 87 & 0.001 & 1,660 & 17 & 2.35 & 0.01 & 209 & 5 & 0.56 \\
\hline НB 101 & 0.01 & 579 & 79 & 50.7 & 0.01 & 109 & 22 & 0.34 \\
\hline HB 102 & 0.1 & 1,901 & 33 & 59.1 & neg. & 49 & 4 & 1.8 \\
\hline HB 117 & 0.01 & 447 & 36 & 20.1 & 0.1 & 106 & 5 & 2.5 \\
\hline НB 149 & 0.001 & 296 & 46 & 14.7 & 1 & 45 & 1 & 0.61 \\
\hline YJ 1 & 0.1 & 98 & 4 & 1.02 & 0.0001 & 3,132 & 5 & 16 \\
\hline YJ 19 & neg. & 10 & 1 & 4.95 & 1 & 2,044 & 3 & 3.35 \\
\hline YJ 24 & neg. & 203 & 5 & 3.04 & 0.1 & 3,200 & 60 & 6.73 \\
\hline YJ 86 & neg. & 298 & 57 & 9.94 & 0.1 & 3,200 & 78 & 4.9 \\
\hline YJ 88 & neg. & 53 & 0 & 1.16 & 0.001 & 2,239 & 85 & 50.9 \\
\hline YJ 89 & 1 & 93 & 6 & 1.98 & 0.0001 & 946 & 74 & 15.4 \\
\hline YJ 94 & neg. & 111 & 2 & 1 & 0.001 & 2,815 & 63 & 1.91 \\
\hline YJ 100 & 0.1 & 39 & 8 & 6.48 & 0.1 & 11 & 4 & 6.67 \\
\hline YJ 115 & neg. & 64 & 16 & 0.34 & 0.01 & 2,417 & 89 & 0.81 \\
\hline YJ 121 & neg. & 92 & 6 & 8.76 & 0.0001 & 2,970 & 85 & 100 \\
\hline YJ 127 & neg. & 139 & 4 & 0.52 & 0.01 & 3,180 & 52 & 1.08 \\
\hline YJ 129 & 0.01 & 123 & 2 & 10.7 & 0.01 & 1,489 & 12 & 8.35 \\
\hline YJ 132 & 0.1 & 146 & 3 & 0.34 & 0.01 & 302 & 3 & 3.61 \\
\hline YJ 133 & neg. & 62 & 6 & 0.6 & 1 & 404 & 28 & 100 \\
\hline YJ 137 & neg. & 199 & 5 & 0.4 & 1 & 292 & 25 & 0.8 \\
\hline YJ 138 & neg. & 172 & 12 & 0.35 & 0.01 & 3,200 & 73 & 4.88 \\
\hline YJ 140 & neg. & 119 & 6 & 4.99 & 0.001 & 1,084 & 49 & 100 \\
\hline YJ 146 & neg. & 211 & 3 & 6.03 & 0.001 & 171 & 17 & 15.1 \\
\hline YJ 148 & 0.01 & 51 & 2 & 1.97 & 0.01 & 49 & 43 & 0.39 \\
\hline YJ 151 & 1 & 48 & 6 & 0.36 & 0.01 & 1,223 & 44 & 0.34 \\
\hline YJ 152 & neg. & 159 & 1 & 1.03 & 0.001 & 102 & 49 & 16.8 \\
\hline YJ 153 & neg. & 103 & 4 & 4.92 & 0.001 & 528 & 26 & 13.3 \\
\hline YJ 154 & 1 & 80 & 9 & 0.84 & 0.01 & 1,702 & 48 & 1.8 \\
\hline
\end{tabular}

The numbers of correctly negative and falsely positive results are shown. The figures in parentheses are the results of patients in whom all 4 test results were available. The individual patients' results from table $4 \mathrm{a}$ with positive results for the nonculprit insect (in bold letters) are represented in table $4 \mathrm{~b}$. Neg. = Negative. ${ }^{\mathrm{a}} \mathrm{p}<0.01,{ }^{\mathrm{b}} \mathrm{p}<0.0001$ for CAST-ELISA; ${ }^{\mathrm{c}} \mathrm{p}<0.01,{ }^{\mathrm{d}} \mathrm{p}<0.05,{ }^{\mathrm{e}} \mathrm{p}<0.0001$ for Flow-CAST. Numbers of HB-positive/YJ-negative cases analyzed by Flow-CAST were too low to reach statistical significance. 
small numbers of patients and/or controls investigated. This makes comparison between studies and transferability of the results difficult. This study uses well-established, commercially available and highly standardized test procedures so that laboratory-related variations in performance can be excluded. This should grant a high interlaboratory reproducibility and reduce the diversification of methods to be used in the future.

A number of controlled studies demonstrated the high sensitivity of CAST-ELISA in hymenoptera-allergic patients between 68 and 100\% [4, 8, 24-26]. Studies by Maly et al. $[27,28]$ on $23 \mathrm{HB}$ - or YJ-allergic patients showed the sensitivity of CAST-ELISA to be higher in patients with positive ST (88\%) than in patients with negative ST (66\%). Also, CAST-ELISA was positive in $87 \%$ of the patients with clinical history but negative ST and sIgE. In all cases, the reported sensitivity of CAST-ELISA was superior to that of ST (76-85\%) and sIgE (70-87\%). The specificity of CAST-ELISA in these studies [4, 25-28] varied between 67 and 100\%; however, control groups were not uniformly selected and tested among these studies [1519]. For the interpretation of the above results it has also to be taken into consideration that ST were not uniformly performed and are only barely standardized.

The overall sensitivity of the various flow-cytometric methods in 10 controlled HB and/or YJ studies [4, 29-37] varied significantly, as well as the methods used and the populations tested (table 6). In a recent publication on 57 patients with systemic reactions to hymenoptera, Eberlein-König et al. [34] admonish the fact that data on BAT for $\mathrm{HB}$-allergic and $\mathrm{HB} / \mathrm{YJ}$-allergic patients investigated with the exact same method are not available.

SIT is a very effective therapeutic means in hymenoptera venom-allergic patients. Due to possible risks of anaphylactic reactions during therapy [38] and a usual duration of 3-5 years, the indication for SIT requires an unequivocal diagnosis which is sometimes difficult with the standard diagnostic means $[10,11]$. Reliable, easily accessible parameters are still to be found to determine the efficacy of immunotherapy. Kosnik et al. [35] correlated the likelihood of side effects under SIT with the degree of basophil sensitivity to allergen-specific in vitro stimulation in 34 patients. Eberlein-König et al. [39], however, could not reproduce these results in their patient collective of 57 patients, but that may be attributable to variations in methodology.

One of the aims of this study was the revised determination of clinical cutoff values for positivity of CASTELISA and Flow-CAST on a large, well-defined patient collective. Sensitivities and specificities of $\mathrm{HB}$ and $\mathrm{YJ}$

Cellular in vitro Assays in the Diagnosis of Hymenoptera Venom Allergy
Table 5. Correlation between the severity of the anaphylactic reaction of each patient and individual test results

\begin{tabular}{lllll}
\hline & CAST & Flow-CAST & CAP-FEIA & ST \\
\hline HB & 0.6466 & 0.0999 & 0.5984 & 0.0083 \\
YJ & 0.9850 & 0.7422 & 0.3526 & 0.5836 \\
\hline
\end{tabular}

The severity of the anaphylactic reaction of each patient was correlated with each individual test result of the different methods using ANOVA on ranks (Kruskal-Wallis $\mathrm{H}$ test).

$\mathrm{p}<0.05$ indicates that the corresponding method may significantly predict the severity of a patient's anaphylactic reaction.

CAST-ELISA were plotted against each other, resulting in ROC curves nearing infinity. Cutoff values were fixed in the bend of the curves at points compromising high sensitivity with reliable specificity (table $1 \mathrm{a}$ and b). These new cutoff values are now set at $270 \mathrm{pg} / \mathrm{ml}$ of sLT release for both $\mathrm{HB}$ and $\mathrm{YJ}$, using $10 \mathrm{ng} / \mathrm{ml}$ of insect venom for stimulation. The same procedure was applied for FlowCAST, yielding a cutoff value of 10\% CD63 expression for both $\mathrm{HB}$ and $\mathrm{YJ}$, using $25 \mathrm{ng} / \mathrm{ml}$ of insect venom for stimulation.

In general, sensitivities and specificities of the cellular allergy assays in our study were somewhat better than sIgE as measured by CAP-FEIA in hymenoptera venom diagnosis, and only slightly surpassed by the ST. This is in contrast to most of the current literature. Sensitivity is said to be higher for CAST-ELISA than for venom-specific IgE [26-28] or both sIgE and ST [4, 8] and higher for BAT than sIgE [32] or both sIgE and ST $[4,30]$. In some of these studies, the differences between the diagnostic means were considerable. For our study, it is striking that although small differences can be observed between the cellular assays, ST and CAP-FEIA, the results are very consistent between the various tests due to vigorous patient selection. The high specificity may be influenced by using skin prick tests in the control group which might be less sensitive than the intradermal test leading to a low false-positive fraction in the control volunteers.

The combined use of CAST-ELISA and Flow-CAST further increases the sensitivity, however with a loss of specificity, when 1 of the 2 assays is positive. All patients who were negative in ST and/or sIgE show a positive result in at least 1 of the cellular assays for both $\mathrm{HB}$ and $\mathrm{YJ}$ venom. Thus, the combination of all 3 methodologies achieves a sensitivity of $100 \%$ or an NPV of 1 (table $1 \mathrm{a}$ and b). Conversely, none of the 44 control subjects was found 
Table 6. Study details and test conditions published in the recent literature

\begin{tabular}{|c|c|c|c|c|c|c|c|c|c|c|c|c|}
\hline Ref. & Specimen & $\begin{array}{l}\text { IL-3 } \\
(2 \mathrm{ng} / \\
\mathrm{ml})\end{array}$ & $\begin{array}{l}\text { Cell } \\
\text { priming } \\
\text { at } 37^{\circ} \mathrm{C} \\
\text { min }\end{array}$ & $\begin{array}{l}\text { Incubation } \\
\text { with aller- } \\
\text { gen at } \\
37^{\circ} \mathrm{C} \text {, min }\end{array}$ & $\begin{array}{l}\text { Range of allergen } \\
\text { concentrations } \\
\text { tested, } \mathrm{ng} / \mathrm{ml}\end{array}$ & $\begin{array}{l}\text { Basophil } \\
\text { selection } \\
\text { marker }\end{array}$ & $\begin{array}{l}\text { Basophil } \\
\text { activation } \\
\text { marker }\end{array}$ & $\begin{array}{l}\text { Healthy } \\
\text { con- } \\
\text { trols, } \\
\text { n }\end{array}$ & $\begin{array}{l}\text { Venom- } \\
\text { allergic } \\
\text { subjects } \\
\mathrm{n}\end{array}$ & $\begin{array}{l}\text { Sensi- } \\
\text { tivity, \% }\end{array}$ & $\begin{array}{l}\text { Speci- } \\
\text { ficity, } \%\end{array}$ & $\begin{array}{l}\text { Optimum } \\
\text { allergen } \\
\text { concentra- } \\
\text { tion, } \mathrm{ng} / \mathrm{ml}\end{array}$ \\
\hline 41 & $\begin{array}{l}\text { heparinized } \\
\text { blood }\end{array}$ & no & no & 15 & 1,000 & $\begin{array}{l}\text { anti- } \\
\text { CD203c }\end{array}$ & $\begin{array}{l}\text { anti- } \\
\text { CD203c }\end{array}$ & 9 & 47 & $85-91$ & 100 & 1,000 \\
\hline 30 & $\begin{array}{l}\text { heparinized } \\
\text { blood }\end{array}$ & no & no & 15 & $10-10,000$ & anti-IgE & $\begin{array}{l}\text { anti- } \\
\text { CD203c }\end{array}$ & 13 & 22 & $83-94$ & $85-100$ & 1,000 \\
\hline 36 & $\begin{array}{l}\text { heparinized } \\
\text { blood }\end{array}$ & no & 10 & 20 & $10-1,000$ & anti-IgE? & $\begin{array}{l}\text { anti- } \\
\text { CD203c }\end{array}$ & 18 & 43 & 97 & 89 & $100-1,000$ \\
\hline 29 & $\begin{array}{l}\text { heparinized } \\
\text { blood }\end{array}$ & no & no & 40 & $10-500$ & $\begin{array}{l}\text { anti-IgE+/ } \\
\text { anti-CD45+ }\end{array}$ & $\begin{array}{l}\text { anti- } \\
\text { CD63 }\end{array}$ & 8 & 26 & 77 & $88-100$ & 500 \\
\hline 32 & $\begin{array}{l}\text { heparinized } \\
\text { blood }\end{array}$ & yes & 10 & 20 & $0.5-50,000$ & anti-IgE & $\begin{array}{l}\text { anti- } \\
\text { CD63 }\end{array}$ & 20 & 50 & 92 & 80 & $500-5,000$ \\
\hline 33 & $\begin{array}{l}\text { heparinized } \\
\text { blood }\end{array}$ & yes & 10 & 20 & $4-4,000$ & anti-IgE & $\begin{array}{l}\text { anti- } \\
\text { CD63 }\end{array}$ & 12 & 20 & 100 & 100 & $400-4,000$ \\
\hline 34 & $\begin{array}{l}\text { heparinized } \\
\text { blood }\end{array}$ & yes & 10 & 20 & $10-1,000$ & anti-IgE & $\begin{array}{l}\text { anti- } \\
\text { CD63 }\end{array}$ & 10 & 18 & $97-100$ & 100 & 1,000 \\
\hline 36 & $\begin{array}{l}\text { heparinized } \\
\text { blood }\end{array}$ & yes & 10 & 20 & $10-1,000$ & anti-IgE & $\begin{array}{l}\text { anti- } \\
\text { CD63 }\end{array}$ & 18 & 43 & 89 & 100 & $100-1,000$ \\
\hline 37 & $\begin{array}{l}\text { heparinized } \\
\text { blood }\end{array}$ & yes & no & 20 & $5-5,000$ & anti-IgE & $\begin{array}{l}\text { anti- } \\
\text { CD63 }\end{array}$ & 14 & 80 & 84 & 100 & 5,000 \\
\hline 35 & $\begin{array}{l}\text { heparinized } \\
\text { blood }\end{array}$ & yes & no & 15 & $100-1,000$ & $\begin{array}{l}\text { anti- } \\
\text { CD123+/ } \\
\text { anti- } \\
\text { HLA-DR- }\end{array}$ & $\begin{array}{l}\text { anti- } \\
\text { CD63 }\end{array}$ & 10 & 34 & 100 & $70-100$ & 1,000 \\
\hline 31 & $\begin{array}{l}\text { PBMS } \\
\text { (citrated } \\
\text { blood) }\end{array}$ & no & no & 30 & $0.1-10,000$ & $\begin{array}{l}\text { anti- } \\
\text { CD123+/ } \\
\text { anti- } \\
\text { HLA-DR- }\end{array}$ & $\begin{array}{l}\text { anti- } \\
\text { CD63 }\end{array}$ & 30 & 23 & $85-91$ & $83-90$ & $100-1,000$ \\
\hline 4 & $\begin{array}{l}\text { buffy coat } \\
\text { (EDTA blood) }\end{array}$ & yes & 15 & 45 & $20-500$ & anti-IgE & $\begin{array}{l}\text { anti- } \\
\text { CD63 }\end{array}$ & 12 & 12 & 100 & 100 & $20-500$ \\
\hline $\begin{array}{l}\text { This } \\
\text { study }\end{array}$ & $\begin{array}{l}\text { plasma } \\
\text { leukocytes } \\
\text { (EDTA blood) }\end{array}$ & yes & no & 40 & $5-25$ & anti-IgE & $\begin{array}{l}\text { anti- } \\
\text { CD63 }\end{array}$ & 39 & 100 & $89-91$ & $95-97$ & 25 \\
\hline
\end{tabular}

to be positive with all 3 methods, neither with $\mathrm{HB}$ nor with YJ venom. Thus, the diagnostic work-up consequently using all 3 methodological approaches as presented in this study not only leads to $100 \%$ sensitivity, but also to $100 \%$ specificity or a PPV of 1 . Overall, CASTELISA and Flow-CAST can be considered valuable additional therapeutic options in determining the culprit insect, especially for those patients with contradictory clinical and laboratory findings.

The total agreement of the different methods with the clinical diagnosis is consistently high (table 2 ; $\mathrm{K}$ values 0.81-0.91) except for HB in CAP-FEIA $(K=0.77)$. Not surprisingly, the concordance between the different methods is also high with K values between 0.69 and 0.82 . However, the correlation of absolute results obtained by the different in vivo and in vitro methods is weak or not existent (table 3). We could not demonstrate a positive correlation of the absolute value of either sLT release or CD63 expression with the severity of clinical symptoms to the insect sting (table 5), as previously reported [31]. Interestingly, we observed a weak correlation between the severity of symptoms to HB stings and the individual reactions to intradermal ST ( $p=0.0083)$, but not in the case of YJ stings. The relatively weak or nonexistent cor- 
relations among the 3 methods on the one hand and between laboratory tests including ST and clinical symptoms on the other hand, suggest that different mechanisms are involved in anaphylaxis, probably also including non-IgE-dependent mechanisms.

In up to $50 \%$ of patients who have been stung and who systemically reacted to one insect, the currently applied diagnostic methods show positivity for both $\mathrm{HB}$ and $\mathrm{YJ}$ $[10,11]$. Hemmer et al. [10] showed that this double positivity on the IgE level is largely due to cross-reactive carbohydrate determinants with low clinical relevance, thus suggesting a probably negligible in vitro phenomenon. A clear differentiation between true double sensitization and clinically probably irrelevant double reactivity, especially with respect to a possible desensitization therapy, is mandatory - even more so if the culprit insect has not been recognized by the patient. The relative specificity of the methods for the culprit insect is shown in table $4 \mathrm{a}$. Both CAST-ELISA and Flow-CAST exhibit a much higher relative specificity in this respect than any other meth$\mathrm{od}$. The reciprocal value of the relative specificities in table $4 \mathrm{a}$ represents the percentage of nonrelevant sensitization in patients with double positivity in the other tests. This could be explained by the fact that cross-linking $\operatorname{IgE}$ and cross-reactive carbohydrate determinants do not play a role in the cellular assays which, therefore, are more likely to detect true, relevant sensitizations than CAPFEIA. This is probably the most relevant additional information to be gained by the cellular assays in the diagnosis of hymenoptera venom allergy. Eberlein-König et al. [40] and Kosnik et al. [35] demonstrated the same problem in 14 patients with inconsistent results between clinical history, ST and CAP-FEIA. They state that the additional performance of cellular tests may be helpful in difficult cases where history, ST and determination of sIgE do not allow a clear decision regarding the relevant insect species for immunotherapy. Binder et al. [41] have also pointed out that there are clinically nonrelevant double reactions as measured by sIgE which can be resolved by the use of BAT in combination with single purified or recombinant protein determinants originating from bee and wasp venoms.

The cellular assays measuring de novo formed mediators are probably superior to the histamine release test that has sometimes been used in experimental settings [4, $27-29,40]$, although it never developed into a widely used routine diagnostic procedure due to the fact that histamine release can also be triggered by nonspecific basophil activators that are present in $\mathrm{HB}$ and $\mathrm{YJ}$ venom extracts [42]. Maly et al. [27, 28] even demonstrated a dissociation of histamine release and sLT formation. Others, however, report a good correlation between the 2 techniques [4, 29-30].

In summary, the diagnosis of hymenoptera venom allergy should not be made upon the result of a single in vitro or in vivo test alone, but several diagnostic methods should be taken into consideration. CAST-ELISA and Flow-CAST are valuable diagnostic tools with special importance in establishing the culprit insect in patients with unclear clinical history and possibly nonrelevant double reactivity in ST and/or CAP-FEIA (sIgE).

\section{References}

-1 Golden DBK, Valentine MD, Kagey-Sobotka A, Liechtenstein LM: Prevalence of Hymenoptera venom allergy. J Allergy Clin Immunol 1982;69:124.

$\checkmark 2$ Charpin D, Birnbaum J, Lanteaume A, Vervloet D: Prevalence of allergy to Hymenoptera stings in different samples of the general population. J Allergy Clin Immunol 1992;90: 331-334.

-3 Rueff F, Przybilla B, Müller U, Mosbech H: The sting challenge test in Hymenoptera venom allergy. Allergy 1996;51:216-225.

-4 Sainte-Laudy J, Sabbah A, Drouet M, Lauret MG, Loiry M: Diagnosis of venom allergy by flow cytometry: correlation with clinical history, skin tests, specific IgE, histamine and leukotriene $\mathrm{C} 4$ release. Clin Exp Allergy 2000;30:1166-1171. $\checkmark 5$ Mosbech H: Death caused by wasp and bee stings. Allergy 1983;38:195-200.

6 Van der Linden PWG, Hack CE, Struyvenberg A, van der Zwan JK: Insect-sting challenge in 324 subjects with a previous anaphylactic reaction: current criteria for insect-venom hypersensitivity do not predict the occurrence and the severity of anaphylaxis. J Allergy Clin Immunol 1994;94:151159.

7 Golden DBK, Kagey-Sobotka A, Normann PS, Hamilton RG, Lichtenstein LM: Insect sting allergy with negative venom skin test responses. J Allergy Clin Immunol 2001;107: 897-901.
8 Anliker MD, Bucher C, Wüthrich B: Entscheidender Nachweis hochgradiger Hymenopterengiftallergie mittels allergenspezifischer Sulfido-Leukotrienfreisetzung aus Basophilen. Allergo J 2003;12:S53-S66.

9 Goldberg A, Confino-Cohen R: Timing of venom skin tests and IgE determinations after insect sting anaphylaxis. J Allergy Clin Immunol 1997;100:182-184.

10 Hemmer W, Focke M, Kolarich D, Wilson IB, Altmann F, Wöhrl S, et al: Antibody binding to venom carbohydrates is a frequent cause for double positivity to honey bee and yellow jacket venom in patients with stinging-insect allergy. J Allergy Clin Immunol 2001;108:1045-1052.

11 Hamilton RG: Diagnostic methods of insect sting allergy. Curr Opin Allergy Clin Immunol 2004;5:209-212. 
12 De Weck AL, Stadler BM, Urwyler A, Wehner HU, Bühlmann RP: Cellular allergen stimulation test - a new dimension in allergy diagnosis. ADI News 1993;5:9-14.

13 De Weck AL: Zellulärer Allergen-Stimulierungstest (CAST). Eine Übersicht und kritische Auswertung der klinischen Anwendung in der Allergiediagnose. Allergologie 1997;20:487-502.

14 De Weck AL, Sanz M: Cellular Allergen Stimulation Test (CAST) 2003, a review. J Invest Allergol Clin Immunol 2004;14:253273.

15 Calafat J, Janssen H, Knol EF, Weller PF, Egesten A: Ultrastructural localization of Charcot-Leyden crystal protein in human eosinophils and basophils. Eur J Haematol 1997;58:56-66.

-16 Knol EF, Mul FP, Jansen H, Calafat J, Roos D: Monitoring human basophil activation via CD63 monoclonal antibody 435. J Allergy Clin Immunol 1991;88:328-338.

17 De Weck AL, Sanz ML: Flow cytometric cellular allergen stimulation test (FAST/FlowCAST): technical and clinical evaluation of a new diagnostic test in allergy and pseudo-allergy. ACI Int 2002;14:204-215.

-18 Sanz ML, Maselli JP, Gamboa PM, Oehling A, Dieguez I, De Weck AL: Flow cytometric basophil activation test: a review. J Invest Allergol Clin Immunol 2002;12:143-154.

19 Ebo DG, Hagendorens MM, Bridts CH, Schuerwegh AJ, De Clerck LS, Stevens WJ: In vitro allergy diagnosis: should we follow the flow? Clin Exp Allergy 2004;34:332-339

20 Mueller HL: Diagnosis and treatment of insect sensitivity. J Asthma Res 1966;3:331333.

-21 Bernstein IL, Storms WW: Practice parameters for allergy diagnostic test. Task force on practice parameters for the diagnosis and treatment of asthma. The American Academy of Allergy, Asthma and Immunology and the American College of Allergy, Asthma and Immunology. Ann Allergy Asthma Immunol 1995;75:543-625.

22 Riske F, Hakimi J, Mallamaci M, Griffin M, Pilson B, Tobkes N, et al: High affinity human IgE receptor (FceRI): analysis of functional domains of the $\alpha$-subunit with monoclonal antibodies. J Biol Chem 1991;266: $11245-11251$.
23 Szymanski W, Hanczaruk M, Rogalewska AM, Michalska I: The CAST-ELISA test in monitoring specific immunotherapy and in differentiation between allergic and pseudoallergic reactions to hymenoptera venoms. Int Rev Allergol Clin Immunol 1999;5:209212.

24 Höxtermann S, Auer T, Altmeyer P: Zelluläre in vitro Diagnostik mittels CAST-ELISA: Leukotriennachweis bei Wespengiftallergie. Allergologie 1995;16:287-291.

25 Cahen YD, Maly FE, Wüthrich B: Cellular Antigen Stimulation Test (CAST) -Verwendbarkeit in der Diagnostik von Insektengiftallergien. Schweiz Med Wochenschr 1997;127: 5-11.

26 Hipler UC, Schlenvoigt G, Bauer A, Gebhardt M, Elsner P: Der Zellantigenstimulationstest (CAST) in der Diagnostik von Allergien und Intoleranzreaktionen auf $\mathrm{Hy}$ menopterengifte. Allergologie 1999;22:481486.

27 Maly FE, Marti-Wyss S, Blumer S, CuhatStark I, Wüthrich B: Interleukin-3 facilitated blood mononuclear cell sulfido-leukotriene generation and whole blood histamine release in honey bee and yellow jacket venom allergy. ACI Int 1996;8:111-125.

28 Maly FE, Marti-Wyss S, Blumer S, CuhatStark I, Wüthrich B: Mononuclear blood cell sulfidoleukotriene generation in the presence of interleukin-3 and whole blood histamine release in honey bee and yellow jacket venom allergy. J Invest Allergol Clin Immunol 1997;7:217-224.

29 Lambert C, Guilloux L, Dzviga C, Gourgaud-Massias C, Genin C: Flow cytometry versus histamine release analysis of in vitro basophil degranulation in allergy to hymenoptera venom. Cytometry B Clin Cytom 2003;52:13-19.

30 Platz IJ, Binder M, Marxer A, Lischka G, Valent $\mathrm{P}$, Bühring $\mathrm{HJ}$ : Hymenoptera-venominduced upregulation of the basophil activation marker ecto-nucleotide pyrophosphatase/phosphodiesterase 3 in sensitized individuals. Int Arch Allergy Immunol 2001; 126:335-342.

31 Sturm GJ, Böhm E, Trummer M, Weiglhofer I, Heinemann A, Aberer W: The CD63 basophil activation test in Hymenoptera venom allergy: a prospective study. Allergy 2004;59: 1110-1117.

- 32 Erdmann SM, Sachs B, Kwiecien R, MollSlodowy S, Sauer I, Merk HF: The basophil activation test in wasp venom allergy: sensitivity, specificity and monitoring specific immunotherapy. Allergy 2004;59:11021109.
33 Freitag M, Höxtermann S, Freitag AP, Straube M, von Kobyletzki G, Altmeyer P, et al: Flowzytometrische Messung der Aktivierung basophiler Granulozyten zur Diagnose der Wespengiftallergie. Allergologie 2001;24:2-8.

34 Eberlein-König B, Schmidt-Leidescher C, Rakoski J, Behrendt H, Ring J: In vitro basophil activation using CD63 expression in patients with bee and wasp venom allergy. J Investig Allergol Clin Immunol 2006;16:5-10.

35 Kosnik M, Silar M, Bajoric N, Music E, Korosec R: High sensitivity of basophils predicts side-effects in venom immunotherapy. Allergy 2005;60:1401-1406.

36 Eberlein-König B, Varga R, Mempel M, Darsow U, Behrendt H, Ring J: Comparison of basophil activation tests using CD63 of CD203c expression in patients with incest venom allergy. Allergy 2006;61:1084-1085.

37 Ebo DG, Hagendorens MM, Schuerwegh AJ Beirens LM, Bridts CH, De Clerck LS, et al: Flow-assisted quantifaction of in vitro activated basophils in the diagnosis of wasp venom allergy and follow-up of wasp venom immunotherapy. Cytometry B Clin Cytom 2007;72:196-203.

-38 Anonymus: Fatal course of Vespula venom immunotherapy: pretreatment withdrawal of the beta blocker may have been involved. Novartis Found Symp 2004;257:226-227.

39 Eberlein-König B, Schmid-Leidescher C, Behrendt H, Ring J: Predicting side-effects in venom immunotherapy by basophil activation? Allergy 2006;61:897.

40 Eberlein-König B, Rakoski J, Behrendt H, Ring J: Use of CD63 expression as marker of in vitro basophil activation in identifying the culprit in insect venom allergy. J Invest Allergol Clin Immunol 2004;14:10-16.

41 Binder M, Fierlbeck G, King TP, Valent P, Bühring HJ: Individual hymenoptera venom compounds induce upregulation of the basophil activation marker ectonucleotide pyrophosphatase/phosphodiesterase 3 (CD203c) in sensitized patients. Int Arch Allergy Immunol 2002;129:160-168.

42 Sidiropoulos J, Papastavrou T, Charissoulis S, Chamalidou C, Lioliou M, Panteliadis C: The cellular allergen stimulation test (CAST): new perspectives in allergy diagnosis? Allergy 1995;50(suppl 26):245. 